\title{
Contribución a la ontología animista andina: funciones, poderes y figuras en los cultos telúricos de los Andes sur-peruanos
}

\author{
Daniela DI SALVIA \\ Centro de Investigación y Promoción Andino-Amazónico SAMI \\ daniela.disalvia@gmail.com
}

Recibido: $6 / 11 / 2015$

Aceptado: 8/9/2016

\begin{abstract}
RESUMEN
En este artículo se analizan los aspectos simbólicos con los que la cosmovisión quechua-andina humaniza el medio ambiente y lo incluye en una dimensión social en la que determinados elementos, fenómenos naturales y seres animales viven y actúan de manera análoga a los seres humanos. Con base en datos etnográficos recopilados en dos comunidades campesinas peruanas sobre el simbolismo de los cultos telúricos, se explica cómo esta humanización constituye una forma de interacción simbólica que los quechuas mantienen con su entorno ambiental, y especialmente con parajes topográficos como la tierra y las montañas, para comprender y propiciar sus austeros mecanismos ecológicos. Al mismo tiempo, se propone una categorización teórica del proceso de simbolización de la tierra andina y sus diversas facetas biológicas, contextualizando en nuestro caso etnográfico nociones antropológicas de las Older y New Ecologies. La finalidad es establecer una continuidad analítica con los estudios antropológicos sobre la cosmovisión religiosa andina y, asimismo, contribuir al interés que la Antropología americanista manifiesta actualmente hacia la búsqueda de definiciones científicas más acordes con las cosmovisiones amerindias y el modo en que éstas describen los seres y elementos «no-humanos» que comparten espacios y representaciones con los seres humanos.
\end{abstract}

Palabras clave: Cosmovisión andina, Perú, ecología simbólica, Pachamama, cultos telúricos.

\section{A Contribution to the Andean Animistic Ontology: Roles, Powers and Figures in Telluric Worships of South-Peruvian Andes}

\begin{abstract}
This article analyzes the symbolic aspects with which the Quechua Andean worldview humanizes the Andean environment, and includes it in a social dimension in which some natural elements, phenomena and animal beings live and act similarly to humans. Based on ethnographic data collected in two Peruvian rural communities about the symbolism of the telluric worship, it is explained how this humanization is a form of symbolic interaction that Quechua people keep with their environment, and especially with topographic places like earth and mountains, in order to understand and propitiate their rigid ecological mechanisms. At the same time, the article proposes a theoretical categorization of the symbolization process of the Andean earth and its varied biological aspects, by contextualizing to the ethnographic case some anthropological notions of the Older and New Ecologies. The aim is to establish an analytic continuation with other anthropological studies about the Andean religious worldview, and to contribute to the interest of the Americanist Anthropology currently in finding scientific definitions more suitable to the Amerindian worldviews, and to how they describe the «nonhumans» beings and elements that share spaces and representations with the human beings.
\end{abstract}

Key words: Andean worldview, Peru, symbolic ecology, Pachamama, telluric cults.

Sumario: 1. Introducción. 2. Medio ambiente y cosmovisión religiosa en los Andes del Cuzco. 3. Significados y funciones: concepciones personalizadas de la tierra. 4. Formas y poderes: cosmología y socialización del ecosistema telúrico. 5. Figuras y acciones: personificaciones telúricas y reciprocidad humano-ambiental. 6. A manera de conclusión: propuestas ontológicas sobre el animismo telúrico andino. 7. Referencias bibliográficas. 


\section{Introducción}

Desde hace más de medio siglo, las relaciones entre las sociedades humanas y el medio ambiente en el que éstas desarrollan su existencia material y hábitos culturales, constituyen un foco de interés primario para algunas líneas de investigación de la Antropología actual. En particular, existen diversas corrientes de pensamiento de la Antropología Ecológica dedicadas al estudio de la interacción material e inmaterial que los humanos mantienen con el mundo no humano (Descola y Pálsson 2001: 25), esto es concretamente, con el medio ambiente y los entes orgánicos e inorgánicos que lo componen. A medida que se han replanteado las herramientas y dominios teóricos del análisis socio-cultural, sobre todo dejando atrás la «reliquia de la dicotomía entre naturaleza y cultura» (Descola 2001: 120), estos enfoques de marco ecológico han ido centrando sus análisis interpretativos en los modelos culturales que las comunidades humanas manifiestan en relación con su medio ambiente. Denominados generalmente como New Ecologies («nuevas ecologías»), se caracterizan sobre todo como enfoques híbridos en cuanto se remiten no sólo al legado teórico de las Older Ecologies («más viejas ecologías»), sino también al de otras sub-disciplinas como la Economía Política, la Antropología Histórica o la Antropología Simbólica. Y es en particular de ésta última de la que se derivan perspectivas interesadas en las creencias y praxis simbólicas que los grupos humanos construyen en relación con su entorno ambiental inmediato, como es el caso del enfoque ecológico-simbólico planteado por Philippe Descola (1993, 1996, 2001, 2012).

La trayectoria de investigación que la Ecología Simbólica mantiene dentro de las New Ecologies ha heredado el mismo interés que la Antropología Ecológica del siglo XX tenía hacia los pueblos autóctonos y sus formas de categorizar los recursos, regularizar su uso y preservar el medio ambiente (Kottak 1999: 26). No obstante, este enfoque también indaga cómo las percepciones culturales que estos pueblos tienen de su entorno se caracterizan en términos de continuidades ontológicas, en la medida en que los componentes de su ecosistema local son humanizados e integrados simbólicamente en un modelo de vida social análogo al humano. Al respecto, la obra teórica de Descola puede sin duda considerarse como paradigmática para el estudio de la socialización simbólica de la naturaleza, pues este antropólogo constata cómo para las sociedades achuar de la Amazonía ecuatoriana y peruana «el reino de las relaciones humanas abarca un dominio más amplio que la mera sociedad de los humanos», al englobar «los componentes del medio ambiente que son vistos como parte del dominio social» (Descola 2001: 25).

Más allá de la influencia de la Antropología Estructuralista del siglo XX, es cierto que las teorías descolianas también tienen sus antecedentes en estudios antropológicos precursores de la inviabilidad de la contraposición «naturaleza»/»cultura»: entre éstos, queremos destacar los de Roy Abraham Rappaport (Biersack 1999: 8; Santamarina 2008: 165), y sobre todo su labor intelectual acerca de la importancia antropológica que tiene el explorar tanto la naturaleza de la religión como el lugar de la religión en la naturaleza (Rappaport 2001: 559). Aun siendo un exponente destacado de la Ecología Cultural del siglo XX, Rappaport se sitúa al borde de las tendencias analíticas de su tiempo, por cuanto considera que los grupos humanos actúan según sus propias 
imágenes culturales de la Naturaleza antes que de acuerdo con la estructura real de ésta (Rappaport 1975: 271). Por tanto, algunas de sus obras se proyectan como un puente interpretativo hacia la Antropología Ecológica de estos últimos decenios (Biersack 1999: 5), siendo especialmente su póstuma Ritual y religión en la formación de la humanidad (Rappaport 2001) la que supera las tesis reduccionistas del viejo ecologismo, en favor de la centralidad que la dimensión ritual-religiosa mantiene dentro de la cosmovisión humana y de su relación simbólica con el mundo material.

Por todo ello, con base en investigaciones etnográficas llevadas a cabo en los Andes del Cuzco, a continuación nos proponemos interpretar los procesos simbólicos que subyacen a los cultos locales tributados a la tierra, integrando nociones de las tesis descolianas y rappaportianas que nos ayuden a perfilar los fundamentos cosmológicos de una ontología animista del ecosistema telúrico centro-andino.

\section{Medio ambiente y cosmovisión religiosa en los Andes del Cuzco}

Definimos el ecosistema centro-andino como telúrico porque la tierra en los Andes Centrales mantiene una importancia relevante al ser venerada, ya sea bajo facetas agrícolas o silvestres, llanas o accidentadas, como un ser vivífico cuyas capacidades productivas aseguran la continuidad vital de hombres y rebaños animales. Llamada principalmente Pachamama y vinculada a otros elementos telúricos como las montañas (o $A p u)$, su culto es de origen prehispánico, pero coexiste con creencias y prácticas religiosas de marco cristiano. Se fundamenta, además, en ofrendas rituales con las que se alimenta a la tierra a fin de que ésta proporcione la salubridad y los bienes agropecuarios necesarios para la continuidad de la vida humana y animal en la sierra. Como veremos en detalle, esta búsqueda humana de la «benevolencia telúrica» está estrechamente ligada a la creencia en que la tierra manifiesta las mismas necesidades de alimentación que los hombres, y puede castigarlos con la pérdida de cultivos o rebaños si éstos no le recompensan por las benevolencias productivas recibidas a lo largo del año. En este sentido, el ritual religioso actúa como medio efectivo e impostergable para asegurar esta reciprocidad alimenticia entre ser humano y entidad telúrica.

Existe una amplia literatura antropológica y etnográfica sobre la cosmovisión religiosa centro-andina, en la que se aborda la relación espiritual que los pueblos locales entretejen con la tierra como forma de religiosidad de origen autóctono, o al mismo tiempo integrada con la religión católica popular ${ }^{1}$. En estas investigaciones la tierra suele ser descrita como un ser vivo y consciente, que ejerce un protagonismo determinante en las creencias y rituales religiosos personales y colectivos. Sobre todo aquéllos relacionados con la productividad agropecuaria y el bienestar humano en general. En este sentido, los cultos que se le tributan, tanto en áreas rurales como urba-

\footnotetext{
1 Mariscotti (1978) presenta, por ejemplo, un detallado estudio etnohistórico sobre la religiosidad autóctona de todos los Andes centro-meridionales. En el caso concreto de los cultos telúricos quechuas y sur-peruanos, valgan en cambio como ejemplo: Alabí 1996; Alencastre y Dumézil 1953; Allen 2008; Casaverde, 1970; Flores 1972, 1977, 1998, 2002; Gow y Condori 1976; Marzal 1971, 1985; Núñez del Prado 1970; Tamayo 1970; Tuero 1994; Valderrama y Escalante 1976, 1988.
} 
nas, son normalmente etiquetados bajo terminologías como la de «sobrenaturalidad», que en nuestra opinión es impropia en la medida en que apunta a una trascendencia de los procesos medioambientales, a los cuales veremos que en realidad la tierra está sometida en cuanto elemento material del ecosistema andino.

Los estudios de Rappaport y Descola sobre la religión y la simbolización humana del medio ambiente nos animan, en efecto, a analizar los cultos telúricos prestando la debida atención analítica a factores materiales como la topografía cordillerana, las dinámicas ecológicas y los seres y elementos no humanos que habitan o conforman el ecosistema local alto-andino.

Al respecto, entre los años 2010 y 2013 hemos situado nuestro ámbito de investigación etnográfico en el distrito de Ollantaytambo, ubicado al noreste del departamento sur-peruano del Cuzco. En las alturas de esta zona geográfica conocida mundialmente como Valle Sagrado de los Incas, residen poblaciones andinas de habla quechua que se denominan a sí mismas runakuna ('gente' en el idioma quechua), y que se organizan legislativamente en comunidades campesinas cuyos poblados centrales y anexos periféricos se abren camino a lo largo de diversos valles interandinos: en el de Patakancha se ubican en particular dos núcleos comunitarios, Willoq y Patakancha, que comparten una relativa cercanía geográfica a la capital local de Ollantaytambo (una media de $20 \mathrm{~km}$ ), lo cual les permite tener una participación bastante activa en la economía productiva y en la negociación económica con los centros urbanos del Valle del Vilcanota (di Salvia 2014: 148) ${ }^{2}$. En consonancia con los procesos propios de la organización económico-social andina (Gölte 1980), Las actividades productivas que las comunidades de Willoq y Patakancha mantienen en relación con su ecosistema local se desarrollan principalmente en el ámbito de la agricultura y la ganadería de altura. Por un lado, los runakuna dedican una multitud de parcelas privadas de terreno (chaqra) al cultivo de sembríos de tubérculos y cereales, habilitando las más pequeñas en las inmediaciones de las viviendas familiares y las más extensas en los declives montañosos de sus respectivos territorios colectivos. En cambio, los suelos de origen glacial y los terrenos comunales de rotación agrícola en descanso son aprovechados para el pastoreo cotidiano de los rebaños de camélidos y de los ganados vacunos, equinos y ovinos. En general, debido a la austeridad climática, a la accidentada ubicación de los espacios agro-pastoriles y a la reducida extensión de aquéllos de uso familiar, la tierra es sometida a un complejo sistema de tenencia y uso particular o colectivo, basado en un manejo controlado de los recursos ambientales y productivos disponibles que es concordado a nivel intracomunal e intercomunal y que, en todo caso, alimenta una economía de subsistencia bastante dependiente de las dinámicas biológicas locales (di Salvia 2014: 187 y ss.).

Aparte del control productivo de los recursos y pisos ecológicos en los que se distribuyen los territorios comunales de Willoq y Patakancha, la coexistencia cotidiana con su entorno ambiental supone para los runakuna no sólo un conocimien-

\footnotetext{
2 Fueron especialmente dieciocho los runakuna de Willoq y Patakancha con los que entablamos conversaciones informales y entrevistas semi-estructuradas, a lo largo de seis meses totales de trabajo de campo etnográfico. Todos ellos eran agricultores y ganaderos de entre cuarenta y noventa años, con conocimientos rituales y con los cuales conversábamos en quechua: sus testimonios fueron recogidos en formato audio, y su transcripción en el idioma original, así como su traducción al castellano se encuentra en di Salvia (2014).
} 
to minucioso de cómo éste debe ser manipulado materialmente, sino también una manera integral de existir y actuar que es acorde a la percepción cultural que éstos tienen de los seres, elementos y categorías que lo conforman. Cabe subrayar que en quechua no existe ningún vocablo para designar la Naturaleza física en sí, ya que para referirse a ésta se emplea la paráfrasis «tukuy hinantin pacha: 'todo como pacha'» (Estermann 1998: 175). Es más, en la cosmovisión andina la noción de pacha expresa principalmente una realidad material fundamentada en categorías espaciales/estáticas y temporales/dinámicas (Manga Qespi 1994: 157), que son además circunscritas, concretas, inmediatas, y que se identifican con las condiciones ecológicas propias de un microcosmos (Allen 2008: 343; Bouysse-Cassagne y Harris 1987: 47; Mariscotti de Görlitz 1978: 29 y 136) como lo es por ejemplo el patakanchino. Para los runakuna de Willoq y Patakancha pacha «es lo que nos da los frutos» y que «es pues como nuestra madre» (di Salvia 2014: 240-242), en el sentido de que para ellos es una dimensión vital que dispensa alimento a hombres y rebaños por medio de la producción agraria y vegetal, al igual que lo haría toda madre con su prole (Mejía 2005: 144). Este tipo de noción no es nuevo, si pensamos que ya décadas atrás el antropólogo y filósofo argentino Rodolfo Kusch (1977: 114) identificaba pacha con «un estado de cosas o hábitat, un aquí y un ahora vital, en el cual entra además el alimento», es decir, un bien de sustento que, desde que ocuparon el espacio cordillerano miles de años atrás, los pueblos andinos recaban al transformar productivamente su medio ambiente, ya sea por medio del trabajo agrícola o del aprovechamiento pastoril de los humedales de altura. En este sentido, el patakanchino se presenta como un ecosistema local en el cual pacha se identifica sobre todo con la tierra lugareña y sus ciclos productivos, e implica para ésta significados añadidos (y por tanto simbólicos) que, como iremos viendo a continuación, se pueden estructurar bajo tres correlativas dimensiones ontológicas de categorización: la «personalización», la «socialización» y la «personificación».

\section{Significados y funciones: concepciones personalizadas de la tierra}

En la simbología telúrica patakanchina, la categoría ontológica de la «personalización» se fundamenta en dos procesos simbólicos esenciales que atañen a la tierra andina: por un lado, en la relevancia espiritual que su vitalidad productiva mantiene para los runakuna; por otro lado, en cómo esta vitalidad se relaciona con analogías propias de los seres humanos, como la maternidad, la feminidad y la identidad (di Salvia 2014: 241). En esta construcción interpretativa de símbolos naturales también se encuentra integrado el lenguaje humano, desde el momento en que las palabras intervienen como elementos objetivos que distinguen objetos físicos, sociales o conceptuales unos de otros (Rappaport 2001: 121). Así concretamente, en el idioma quechua la tierra productiva que es pacha se distingue conceptualmente de la tierra que es allpa, es decir, la «materia desmenuzable que constituye el suelo natural» (Cusihuamán 2001: 23). El concepto de «distinción» es relacionado por Rappaport (2001: 119) con la información que son capaces de transmitir, por ejemplo, las taxonomías; y sobre las mismas también ahonda Descola (2012: 242) cuando opina que, entre el 
nombre y las propiedades de un tótem, existe una relación esencialmente metonímica. La utilidad de tales conceptos teóricos estriba en que, aplicados al imaginario colectivo patakanchino, éstos identifican la tierra allpa como una taxonomía orgánica cuyo paradigma intrínseco distintivo es pacha, esto es: la misma tierra material que, sin embargo, es sujeta a mecanismos productivos propios de reproducción vegetal, que los runakuna reconocen y aprovechan a nivel agrícola y pastoril.

Estos mecanismos productivos están en la base de concepciones cosmológicas y prácticas rituales andinas, fundamentadas en la creencia social de que la tierra manifiesta vitalidad precisamente en cuanto produce. Si buena parte de la literatura antropológica andina escrita al respecto etiqueta este acervo de concepciones como parte de un universo religioso sobrenatural, en cambio nosotros preferimos emplear la noción de «numinosidad», originariamente acuñada por el filósofo Rudolf Otto en el siglo XX, y retomada por Rappaport (2001: 523-524) bajo la definición de presencia experimentada emotivamente como «externa al yo», y que «no es simplemente un abstracción sino un ser o, si no es un ser, es algo que posee ser, o está siendo «vivo» activamente».

De acuerdo con nuestras interpretaciones etnográficas, para los runakuna la tierra pacha es numinosa porque está «siendo viva activamente», y esta vitalidad le deriva de su actividad productiva, tanto agraria como vegetal en general; al mismo tiempo, los runakuna asocian esta productividad telúrica a su percepción emotiva de la tierra como un «ser» maternal (la Pachamama), porque sustenta a hombres y rebaños de la sierra patakanchina. Así por ejemplo, Antonio, natural de Willoq, nos comentaba que «la Pachamama en el subsuelo lleva la misma existencia que una mamita y por eso nos otorga sus frutos, nos da los alimentos de este mundo, da a los animales pasto, $\mathrm{y}$ con eso sabemos que tiene vida» (di Salvia 2014: 242). Lo cual pone de manifiesto cómo la experimentación subjetiva-emocional y el conocimiento objetivo-empírico de la realidad ecológica se refuerzan mutuamente en la cosmovisión quechua, y lo hacen bajo las facetas vitales de una Pachamama telúrica que, como recalca su apelativo reverencial, posee atributos de concreción espacio-temporal (pacha-) y de maternidad (-mama).

Al igual que pacha como «taxonomía distintiva», la condición simbólica de madre sustentadora es, por lo tanto, también determinante en la personalización de la tierra andina, ya que revela el carácter netamente femenino de una Pachamama que, como veremos para nuestro caso etnográfico, también se personifica figurativamente en la mujer andina local.

El que los quechuas conciban a la tierra productiva que es pacha como madre y mujer implica, a nuestro juicio, dos importantes inferencias interpretativas. En primer lugar, significados distintos como los de «tierra», «madre» y «mujer» convergen en «similitudes», que son, de acuerdo con Rappaport (2001: 119), características «escondidas detrás de las superficies de fenómenos aparentemente distintivos». En otras palabras, «productividad telúrica», «maternidad» y «feminidad» se presentan como indisociables en la cosmovisión patakanchina, ya que los runakuna afirman, por ejemplo, que la Pachamama «hace crecer sobre ella los alimentos para nosotros sus hijos», «nos cría» y «es como si nos amamantara» (di Salvia 2014: 248-249). En segundo lugar, otra relevancia simbólica determinante radica en que, como madre 
y mujer, la tierra posee por tanto una identidad individual, que suele expresarse por medio de sus apelativos reverenciales ${ }^{3}$. Pachamama es el más conocido y empleado en el área andina de dispersión del culto telúrico (Mariscotti de Görlitz 1978: 25), pero en la región del Cuzco son varios los apelativos personales que, además de éste, definen a la tierra como «ser individual»: Pachatierra, Tierramama, pero sobre todo Juana Puyka o Mama Puyka (en comunidades del Valle Sagrado, ver Núñez del Prado 1970: 74 o di Salvia 2014: 251 y ss.); Juana Saqapani, Juana Qonorani, María Wamantiqlla o Teresa Nust'a (en comunidades de Quispicanchi y Paucartambo, ver Sánchez Garrafa 1995: 177 y di Salvia 2014: 252). Junto con otras variantes como Tomasa Saq'apuma, Tomasa Quinchu, María Pantik'anti o Uray Muhuni, estos apelativos, empleados por los quechuas como si fueran nombres y apellidos humanos reales, normalmente personalizan a la tierra andina aun identificándola materialmente con parajes montañosos específicos o terrenos de cultivos (Flores 1977: 229; di Salvia 2014: 254-256). No obstante, también pueden prefigurar su «personificación» humana, al aparecer en mitos locales aludiendo a doncellas legendarias que mantienen un parentesco filial con alguna cumbre montañosa, y especialmente con el nevado del Ausangate (Flores 1977: 229; Sánchez 1995: 177; Valderrama y Escalante 1978). En todo caso, basándonos en la importancia que Rappaport (2001: 447, 449) asigna al lenguaje sagrado como medio simbólico que infunde veracidad a lo que no es empíricamente demostrable (esto es, la experiencia religiosa de lo numinoso), nosotros consideramos de manera similar que, mediante el uso discursivo de los apelativos sagrados telúricos, los quechuas reafirman las capacidades humanizadas que posee este numen, ya sea para participar en la cotidianeidad patakanchina como sujeto individual materno y femenino, ya sea también para influir sobre ella con conciencia y poderes.

\section{Formas y poderes: cosmología y socialización del ecosistema telúrico}

Dentro de los procesos simbólicos constitutivos de la personalización telúrica, la humanización de este elemento material pasa por concebir que éste posee también una conciencia espiritual y una voluntad de acción. Características personales que determinan su índole comportamental y su poder arbitrario, especialmente ante los quehaceres humanos relacionados con las dinámicas productivas ordinarias. Esto significa que, además que con significados añadidos sobre las funciones efectivas de la tierra, el imaginario colectivo patakanchino se enriquece también con discursos cosmológicos socialmente compartidos, en los cuales la Pachamama suele actuar como dueña y dispensadora de los diversos hechos y fenómenos ecológicos: así por ejemplo, según los runakuna «mantiene los pastos, las plantas, suelta los vientos, cría a los animales»; por su existencia «los árboles crecen, existimos, todo lo que labramos crece»; «fructifica los alimentos»; «hace madurar bien la papa»; «nos provee los terrenos de cultivo y de todo completo» (di Salvia 2014: 248, 249, 251). Bajo estas perspectivas

3 En su análisis sobre el simbolismo de los fetiches benineses, el antropólogo Marc Augé (1998: 82) también señala que más allá de su materialidad es el nombre el que representa la identidad de éstos. 
cosmológicas, la Pachamama ejerce un poder voluntario de acción sobre la ecología patakanchina que tiene características «divinas», pero no en los términos que configuran la fisicidad y arbitrariedad propia de los dioses tradicionales del mundo griegoromano antiguo, sino más bien en los términos en los que Rappaport (2001: 547) califica a lo que: 1) tiene una calidad no material (como son, en nuestro caso, la identidad, feminidad y maternidad telúrica); 2) existe, es o tiene ser (como es la tierra con su identidad personal y, como veremos, con sus semblanzas figurativas específicas); 3) parece estar vivo porque posee algo semejante a la utilidad (como la tierra en su producción agrícola y vegetal humanamente aprovechable); 4) es poderoso o eficaz en la medida en que causa efectos (como aquéllos que la tierra produce en el plano ecológico); y 5) que por su numinosidad es racionalmente incomprensible (como lo es la productividad telúrica, percibida emotivamente por los runakuna como signo de vitalidad).

Cabe subrayar que estos «poderes divinos de acción» sobre las dinámicas ecológicas locales, y por tanto también sobre las propias relaciones humano-ambientales, son protagonizados cosmológicamente por la Pachamama bajo las mismas formas materiales que la constituyen como elemento telúrico. Ésta los ejerce, además, en conjunto con otros elementos y fenómenos del entorno ambiental, que los runakuna también personalizan como númenes que dominan sobre la ecología local con comportamientos análogos a los humanos, y bajo formas materiales propias. Los cerros y cumbres montañosas, que se denominan principalmente como $A p u$, constituyen al respecto un ejemplo representativo, aunque veremos en breve que no el único. Ya descritos por la literatura antropológica centro-andina como «dueños y protectores de la vida» (Earls 1982: 4), uywaqkuna ('los que velan por los hombres', Casaverde 1970: 141) o, por ejemplo, como protectores de los cultivos de tubérculos (Gow y Condori 1976: 41) y «dadores de semilla» (Sánchez 1995: 170), en la cosmología local patakanchina estos elementos telúricos, a ratos tipificados discursivamente por los runakuna en un prototipo conceptual («el $A p u »)$, complementan a la Pachamama como seres personales masculinos que «traen los vientos, ponen los pastos también, ya que están juntos con la tierra; él también nos cría no más como un padre. Nos cuida, son puntas, separa las parcelas, deslinda, orienta» (di Salvia 2014: 274). En este sentido, la Pachamama constituye su «pareja» humanizada, ya que para los runakuna los dos «conversan como si estuvieran conviviendo como marido y mujer»; «viven juntos, y se llaman»; «se encuentran, se llaman por las noches, son como mujer y varón»; «dialogan, conversan del robo del ganado» (di Salvia 2014: 279, 280). Si bien en algunas fuentes etnográficas cuzqueñas se describen creencias locales sobre Apu concebidos como femeninos (más que nada por la morfología montañosa que los caracteriza) $)^{4}$, lo más común es que éstos manifiesten características masculinas basadas en poderes de vigilancia y ordenamiento del entorno ambiental, que condicionan a las colectividades humanas que viven en sus laderas a organizar sus espacios

\footnotetext{
4 En la comunidad de Qotobamba (distrito de P'isaq), el Apu Pukarapantillijlla es considerado femenino por tener una forma cónica muy similar a las faldas de una mujer (Casaverde 1970: 144). Del mismo modo, la comunidad de Accha (provincia de Paruro) venera el Apu Siwina como una mujer reclinada sobre sí misma, embarazada y con las manos sosteniéndose el vientre (Decoster 1994: 54).
} 
poblados y agro-pastoriles a partir de la predominancia de la topografía silvestre altoandina (Ricard 2007: 54-55).

Pero en el imaginario cosmológico patakanchino los Apu no constituyen la única «pareja» humanizada de la Pachamama, ya que la perdurabilidad ecológica de los espacios telúricos productivos representados por ésta depende también de la lluvia, y sobre todo de la relevancia biológica que ésta mantiene para la hidrología atmosférica local (más aún cuando las tierras familiares y comunales del valle de Patakancha producen en régimen de secano). En Willoq, Antonio nos comentaba que son los Apu los que «llaman a la lluvia, colocan las nubes, la sombra», y que «si no hubiera lluvia los cultivos se secarían y la helada los quemaría» (di Salvia 2014: 275). En consonancia con los beneficios biológicos que la tierra experimenta en términos de fertilidad y productividad, esta lluvia que se origina en las nubes montañosas es personalizada por los runakuna como Hanaq Pacha Qarpa porque, más allá del puro fenómeno atmosférico conocido en quechua como para, éstos la conciben como una taxonomía distintiva que identifica el «riego» (qarpa) procedente del «mundo de arriba» (hanaq pacha). Por ello, en las perspectivas cosmológicas de los runakuna, este numen atmosférico ejerce sus poderes divinos de acción como «esposo» de la Pachamama y a la par que los $A p u$, ya que, como se nos decía por ejemplo en Patakancha, «él también es su esposo, y entonces con ese bonito producen papas, maíz, trigo crecen desde la tierra»; y que «cuando llega el Hanaq Pacha Qarpa su esposo, entonces los árboles, los pastos crecen bonito; sí, cuando llega su esposo se encuentran bonito como hombre y mujer con la lluvia» (di Salvia 2014: 278).

En nuestra categorización antropológica, hemos recogido esta ontología ecológica del mundo físico patakanchino bajo el espectro teórico de las técnicas y símbolos de «socialización de la Naturaleza», identificados por Philippe Descola en sus estudios sobre las prácticas sociales que los pueblos amazónicos achuar mantienen con su medio ambiente. De forma similar a cómo éstos «confieren a las plantas y los animales los atributos de la vida social, [...] y no sabrían, por tanto, expulsarlos a una esfera autónoma» (Descola 1993: 440), así los runakuna engloban a tierra, lluvia y montañas dentro de una esfera social sobre la cual influyen con sus capacidades humanizadas de acción y conciencia. Un proceso simbólico de inclusión social del cual, además, no quedan excluidas tampoco otras entidades de la Naturaleza local vinculadas de alguna manera a la Pachamama y los Apu, como son por ejemplo diversas especies animales indómitas para los hombres pero «dóciles» ante sus «dueños» telúricos, a la par que cualquier rebaño andino domesticado ${ }^{5}$.

Como hemos indicado al principio, Descola $(1996: 434 ; 2001: 25 ; 2012: 40)$ apunta a que estas lógicas simbólicas de «socialización» que los seres humanos infunden al medio ambiente circundante representan un continuum del dominio social humano. En nuestro caso concreto, hemos constatado principalmente que la inclusión social de los seres naturales andinos expresa una necesidad humana de comprender la sustancial ajenidad del entorno ambiental, mediante la formulación verbal y conceptual de

\footnotetext{
5 Los runakuna afirman que los $A p u$ crían «a los animales silvestres, a la vizcacha, al venado, al cóndor, al zorro»; que «los animales de la Pachatierra son el sapo, el zorrino, las lagartijas, las lagartijas pequeñas»; y que, más concretamente, «el cóndor es su gallina y el zorro su perro, el puma es su gato, el zorrino su chanchito, la vizcacha su cuy» (di Salvia 2014: 284).
} 
comparaciones analógicas con la identidad individual, así como con la organización familiar, social y agropecuaria de los runakuna. El que la realidad medioambiental circundante (o porciones de ella) sea fundamentalmente ajena al desarrollo vital humano es algo a lo que también Descola (2012: 30-31) alude, al observar que se dan casos en que según los achuar «el gran continuum social en que se mezclan humanos y no-humanos no es enteramente incluyente», ya que «algunos elementos del medio ambiente, carentes de un alma propia, no se comunican con nadie» ${ }^{6}$. En este sentido, la dimensión comunicativa constituye una pieza clave dentro de la construcción social del medio ambiente porque, allá donde se establece, actúa precisamente como un nudo interrelacional simbólico entre los mundos humano y extra-humano. El propio Descola (1996: 436) evidencia de hecho cómo «al dotar la naturaleza de propiedades sociales, los hombres hacen más que conferirle atributos antropomórficos», pues «socializan en lo imaginario la relación ideal que establecen con ella». Así, de acuerdo con nuestras observaciones en el valle de Patakancha (di Salvia 2014: 317), la relación ideal que se establece concretamente entre la tierra y los runakuna tiene su culmen en una comunicación simbólica que, como profundizaremos en breve, suele originarse en la dimensión onírica humana, mediante la aparición de figuras representativas de la Pachamama; e impulsa iniciativas humanas de tipo ritual dedicadas a esta última. Por lo tanto, es una comunicación que sigue una trayectoria circular tierra $\rightarrow$ hombre $\rightarrow$ tierra, que se caracteriza como recíproca y consecuente y en la cual, además, se incorporan a los atributos telúricos de personalización y socialización otros de tipo figurativo, y por tanto más propios de una dimensión telúrica personificada.

\section{Figuras y acciones: personificaciones telúricas y reciprocidad humano- ambiental}

Entre los runakuna existen concepciones arraigadas sobre cómo, junto al protagonismo activo que mantiene en el universo social medioambiental, la Pachamama puede adquirir semblantes figurativos que toman forma en el mundo onírico humano, pero que pueden asimismo llegar a concretarse en la realidad ordinaria. Nos comentaba, por ejemplo, Saturnilla en la comunidad de Willoq que la tierra «te ensueña convirtiéndose en un zorrino; y en tus sueños el zorrino te salta de frente»; que «cuando sueñas con el sapo es también la Pachamama»; o que ésta «te ensueña también en la forma de una mujer», que viste «a la manera de nosotros, con las mismas trenzas» (di Salvia 2014: 299). Este abanico de semblantes figurativos animales y mujeriles que los runakuna atribuyen a la tierra, y que en líneas generales también comparten otras culturas regionales andinas ${ }^{7}$, pone de manifiesto el peso significativo que el cuerpo físico ejerce en las configuraciones simbólicas del imaginario colectivo patakanchino. Son de hecho analogías comparativas que presentan a la tierra como elemento indisociable de ciertas especies animales locales, así como de la identidad estética de

\footnotetext{
6 Los achuar incluyen en este universo salvaje extraño al hombre a la mayoría de los insectos y los peces, los musgos y los helechos, los guijarros y los ríos, cuya existencia es maquinal y genérica (Descola 2012: 31).

7 Remitimos a la exhaustiva recopilación de ejemplos figurativos anfibios y mujeriles, que Mariscotti de Görlitz (1978: 31-53) presenta en su estudio diacrónico de las religiones andinas centro-meridionales.
} 
las mujeres del valle: en las palabras de los runakuna, «el sapo es la tierra, es como su animal»; «el sapo es la tierra, y tomando formas diversas aparece; si es que te sueñas con el sapo es la Pachatierra»; «el zorrino es la Pachatierra también, convertido en zorrino aparece no más la Pachamama» (di Salvia 2014: 301, 305). Asimismo, además de con trenzas, la Pachamama es detallada por los runakuna como una mujer con «rostro blanco», «de cabellera frondosa», que «se parece a una mujer de puna como nosotros; en nuestros sueños nos estamos encontrando con ella»; que «no es mestiza, es siempre como una mujer de puna, viste así como nosotros, no tiene ropa diferente»; y que «se nos puede presentar y nos puede hablar directamente vestida con una ropa brillante» (di Salvia 2014: 291-292).

Como partes integrantes del proceso simbólico de personificación telúrica, estas identificaciones figurativas de la tierra con la mujer patakanchina y con animales que habitan el ecosistema local, se fundamentan en las nociones mismas de fertilidad y productividad que hemos englobado en las categorías ontológicas de la personalización y socialización telúricas. De hecho, el vínculo figurativo entre la tierra productiva y la figura femenina humana pasa simbólicamente por las «potencialidades maternales» que ambas poseen, según hemos anteriormente analizado; mientras que, por su parte, las personificaciones simbólicas de tipo anfibio y mamífero llaman en causa la interdependencia ecológica que existe entre estas especies y los ciclos de producción de la tierra. Los runakuna conocen muy bien las modalidades de esta interdependencia telúrico-animal, y de hecho las explican con argumentos empíricos como que «el zorrino escarba el suelo y también vive en él»; que «el sapo y el zorrino viven bajo el suelo»; o que «el sapo vive con la tierra; crece dentro de la tierra y cuando tiene hambre sale» ${ }^{8}$.

Pero el factor productivo subyace también a otros aspectos relevantes del proceso simbólico de personificación telúrica. Cabe destacar, en efecto, que las configuraciones humanas y animales ideadas por los runakuna conforman una encarnación realmente existente de la tierra andina, porque éstos creen que sus experiencias oníricas tienen la misma veracidad que las que se producen en estado de vigilia, y por consecuencia también implicaciones efectivas sobre la vida ordinaria humana9. Lo cual quiere decir que, en el imaginario social patakanchino, los sueños protagonizados por la tierra personificada funcionan concretamente como un acontecimiento informativo de tipo indéxico, puesto que indican y avisan a los runakuna sobre alguna situación que se puede cumplir en la realidad inmediata, normalmente con consecuencias adversas para la continuidad productiva que éstos intentan asegurarse en sus quehaceres agropecuarios. De hecho, en sus apariciones oníricas la Pachamama suele ostentar una actitud caprichosa, por ejemplo «jaloneando o haciendo otras cosas en los sue-

\footnotetext{
8 La mofeta andina o añas en quechua (género conepatus chinga, Chávez 1950: 285) vive en madrigueras cavadas por las hembras en época de secas, cuando las duras temperaturas invernales la obligan a un letargo temporal, que finaliza alrededor del comienzo de la época de lluvias y del deshielo térmico. De manera análoga los batracios, o hamp'atu en quechua (género bufo vulgaris, Roca 1966: 43), son capaces de resistir períodos prolongados de hibernación dentro de la tierra, para subir a la superficie en temporadas propicias como las de lluvias (Cáceres 2007).

9 Esta concreción propia del sueño se refleja también en la dimensión lingüística ya que, como explica Gerald Taylor (1999: 267), la raíz léxica mus- del verbo quechua mosqhoy ('soñar') «corresponde a la idea de la cognición inmediata, inspirada, transmitida a veces por una visión o un embrujamiento».
} 
ños», pero aún más amenazadora o amonestadora, al recordar a los runakuna que «a ella pues le da sed, le da hambre», y reprocharles que «tú solo estás comiendo, tú solo estás bebiendo, y de mí ni te acuerdas» (di Salvia 2014: 291, 293, 295).

Frente a esas necesidades que la tierra expresa en relación con la comida y la bebida, los runakuna sienten la obligación emotiva y moral de alimentar concretamente a este numen, del mismo modo como se alimentan ellos cotidianamente, pues de no hacerlo éste «te induce a gastos imprevistos; fastidia a tus animales, a tus sementeras, te fastidia en todo», y «hasta puede desatar la muerte» (di Salvia 2014: 295). Alimentar en este caso específico significa para los runakuna no sólo atender a las necesidades humanizadas de la Pachamama mediante ofrendas rituales que satisfagan literalmente sus antojos ${ }^{10}$, sino también propiciar en términos exhortativos su benevolencia en favor de la productividad, ya que en sus palabras «si no nos suplicamos a la Pachamama nuestros alimentos escasean, nuestros animales están sin mucha fuerza y [ella] hace remover nuestra chaqra con el zorrino»; «no maduraría bien lo que habíamos estado trabajando, el tallo de las plantas estaría delgado, el zorrino también lo rompería, lo voltearía, lo arañaría» (di Salvia 2014: 297, 302).

Aunque la literatura centro-andina proporciona escasas referencias en torno a este característico animal omnívoro ${ }^{11}$, lo cierto es que la mofeta es una especie particularmente representativa del potencial comportamiento arbitrario y castigador de la Pachamama, precisamente porque en el ecosistema local sus hábitos vitales suelen ser perjudiciales para la producción agraria familiar. La aprehensión emotiva con la que los runakuna sueñan con este animal se debe a los estragos reales que ocasiona sobre los cultivos de tubérculos, alimento del que se apodera precisamente removiendo la tierra con su hocico o escarbando el suelo, como nos comentaba Saturnilla ${ }^{12}$. Es por ello que los runakuna también lo describen tajantemente como un animal «muy molesto», que «si no le pagas a la Pachatierra podría acabar con la chaqra» (di Salvia 2014: 302), comportamiento éste sin duda adaptativo dentro de las estrategias ecológicas propias de los seres naturales, pero que contrasta netamente con los beneficios productivos que, por el contrario, aportan los anfibios sobre las tierras de labrantío. La presencia de sapos en

10 De manera similar a las ofrendas rituales que se tributan en otras regiones del Cuzco o departamentos limítrofes, y sobre las cuales existen detalladas descripciones etnográficas (valgan entre muchas las de Casaverde 1970; Contreras 1983; Dalle 1969; Fernández 1997; Flores 1998; Tuero 1994), en el valle de Patakancha se ofrendan a la tierra muy diversos ingredientes alimenticios, como semillas y hojas de coca, granos de legumbres (frijoles blancos, garbanzos y lentejas), pasta, pan de anís, azúcar, arroz y otros cereales (kinuwa, kañiwa), golosinas y galletas saladas, granos de maíz blanco y amarillo y otros granos selváticos, grasas animales, y más raramente frutas como naranjas o piñas. Estos alimentos y manjares rebuscados son además asperjados con vinos licorosos como el Oporto, y son enterrados o quemados con la creencia de que realmente la Pachamama y los Apu podrán degustarlo y oler su aroma (di Salvia 2014: 361 y ss.).

11 Hasta donde llegan nuestros conocimientos, la mofeta aparece citada en el manuscrito colonial Dioses y Hombres de Huarochirí, donde se pronostica la aversión que los seres humanos desarrollarían hacia este animal (Millones 2011: 252-253), o en fuentes recientes en las que se describe el uso medicinal de algunas de sus partes corporales (Cayón 1971: 158-159). También figura en relatos orales del sur del Perú, en los que actúa de forma mítica o mágico-adivinatoria, en algunos casos en relación simbólica con los cultos telúricos (Granadino y Jara 1996: 166-168).

12 Ya en la crónica colonial del indio Felipe Guamán Poma de Ayala (1980 [1615]: 467) se menciona, por ejemplo, que septiembre era el mes de «comensar a guardar las sementeras [...] de zurrillas, que ellos les llaman [...] anas [zorrino], que escaruan y buelben a sacallo en todo el rreyno y mucho más en la cordelera de los llanos y de los Andes». 
el subsuelo constituye de hecho un índice biológico de salubridad de los terrenos agrícolas, ya que esta especie trae sustento de la humedad telúrica, garantizando además su protección parasitaria al comer insectos potencialmente perjudiciales (Ortiz 1992: 192; Roca 1966: 59). Así, aunque al igual que la mofeta el sapo también puede manifestar en sus sueños una actitud amenazadora (según Saturnilla «te salta cuando la tierra está de hambre», di Salvia 2014: 299), para los runakuna es esencialmente una especie animal que protagoniza los procesos de producción agrícola en la medida en que propicia activamente su salubridad. En consecuencia, en sus discursos cosmológicos éstos la reverencian verídicamente como «dueña de la chaqra», ya que «gracias a que hay sapos, los productos de la agricultura también son hermosos» (di Salvia 2014: 303).

\section{A manera de conclusión: propuestas ontológicas sobre el animismo telúrico andino}

A la vista de esta interdependencia ecológica que, ya sea beneficiosa o desfavorable, sapos y mofetas mantienen con la productividad agrícola local, observamos que, en términos cosmológicos, estas especies integran el entorno físico patakanchino con la misma conciencia espiritual y capacidad de acción que la que poseen los elementos telúricos y atmosféricos humanizados por los runakuna. Si bien no nos hemos detenido en ello, cabe subrayar que esta integración cosmológica atañe también a otros animales determinantes en la ecología local (como los zorros, que son principalmente depredadores de crías de ovejas y alpacas), así como a parajes topográficos específicos (peñas, rocas, escarpaduras, puntos de agua, etc.), que para los runakuna son igualmente relevantes porque constituyen un peligro potencial para los rebaños que pastan en sus inmediaciones. Según nuestras inferencias interpretativas, nos encontramos por lo tanto ante un mundo físico fragmentado en unidades naturales significativas, que son al mismo tiempo referenciales y animadas, en la medida en que los hechos ecológicos que protagonizan y las materialidades orgánicas que las caracterizan indican que éstas poseen una interioridad anímica propia.

Como sabemos, la condición de «Naturaleza animada» ya fue teorizada por Edward B. Tylor (1981 [1871]: 255), quien la circunscribía esencialmente a la «proyección antropomórfica de la hipótesis del alma sobre los animales, las plantas y los objetos inertes» (Puente y Careaga 2005: 43). No obstante, es sobre todo la Ecología Simbólica de hoy día la que, en el contexto de las cosmovisiones indígenas amazónicas, reformula la noción tyloriana de lo «animado» como una categoría ontológica fundamentada en la creencia cultural de que seres humanos y no-humanos poseen una interioridad de la misma naturaleza (humanizada, precisamente) dentro de sus respectivas fisicalidades corporales (Descola 2012: 90). Bajo estas lógicas las concepciones ecológico-simbólicas patakanchinas, entendidas como modelo ejemplificado de una más amplia variedad de cosmovisiones propias del mundo andino, comparten con las amazónicas un trasfondo imaginativo similar. Por ende, se prestan a categorizaciones afines a éstas, pero sin por ello olvidar las posibilidades de complementación terminológica que brindan los estudios simbólicos de Roy Rappaport, pues a éste se debe la formulación de una semiología comunicativa de los símbolos 
rituales y religiosos en la cual los aspectos materiales y observables son los protagonistas (Jimeno 2006: 39, 89) ${ }^{13}$.

En sus escritos teóricos, Descola (2001: 108; 2012: 192-193) califica a las cosmovisiones animistas como sistemas de identificación que utilizan las categorías elementales de la práctica social para pensar las relaciones de los seres humanos con los seres naturales. Esto es lo que también ocurre en términos simbólicos cuando la cosmovisión patakanchina humaniza (y más concretamente: personaliza, socializa y personifica) a los entes animales y vegetales de su ecosistema específico. Descola (2001: 112-113; 2012: 448) argumenta además que seres humanos y especies naturales interactúan en la praxis social de acuerdo con modos de relación diferenciados: entre éstos, la reciprocidad figura como una forma de transferencia que caracteriza las relaciones simbólicas de intercambio entre humanos y no humanos, lo cual efectivamente ocurre en las relaciones de reciprocidad que los runakuna establecen con los seres y elementos no humanos de su entorno ambiental ${ }^{14}$.

Citando a Descola (2001: 115-116), estas relaciones se basan efectivamente en un «intercambio constante de servicios, almas, alimentos o vitalidad genérica», y en la creencia dominante de que «los humanos tienen una deuda con los no humanos, principalmente por la comida que estos últimos le proporcionan». Además, por más que traten de esquivar sus obligaciones, los humanos reconocen que «es legítimo que los no humanos traten de restaurar el equilibrio de la reciprocidad capturando componentes de la persona humana, participando de su comida o absorbiendo una parte de su vitalidad».

Así concretamente, hemos constatado en nuestro análisis etnográficos que la reciprocidad que los runakuna mantienen con las facetas telúricas de su entorno productivo, tanto agrario como silvestre, requiere un intercambio de alimento cuya continuidad es sin embargo constantemente amenazada por las negligencias humanas. De ahí que los runakuna reconozcan que siempre están en deuda con la Pachamama, o que incluso sea ésta la que se manifieste en sus sueños diciéndoles ««estás en deuda», cuando no le has pagado» (di Salvia 2014: 295), esto es, devuelto lo que le es debido. En este sentido, la deuda que existe entre ser humano y numen es, como subraya en términos generales la antropóloga Ina Rösing (1994: 200), una «deuda de ofrenda» cuya causa es «un déficit del actuar» y que, como hemos indicado anteriormente, sólo se puede extinguir retornando (ritualmente) los beneficios agrícolas y pastoriles recibidos con ofrendas alimenticias, lo suficientemente apreciadas (es decir, simbólicamente eficaces) como para que se restaure el equilibrio humano-ambiental. Un

13 Rappaport (2001: 32, 559) considera que el hombre sólo puede vivir en función de significados que «debe inventar en un mundo desprovisto de significado intrínseco pero sometido a la ley natural»; ejemplos de ellos son las «cosmologías, instituciones, reglas y valores concebidos simbólicamente y determinados mediante acciones performativas».

14 Es bien conocido en la literatura andinista el arraigo social que el concepto de «reciprocidad» tiene, desde épocas tempranas, en la vida local de las comunidades andinas. Los estudios etnohistóricos de Rostworowski (1976: 341) revelan, de hecho, cómo el sistema de reciprocidad ya funcionaba en los Andes prehispánicos como una organización socio-económica que regulaba la prestación de servicios a distintos niveles, y servía de engranaje en la producción y distribución de bienes. Sobre las formas de intercambios recíprocos de bienes y servicios en comunidades campesinas andinas también se detienen, a manera de ejemplo, Gölte (1980) y Sánchez (1982); pero es especialmente Rösing (1994: 194) quien subraya la importancia simbólica que la «reciprocidad» adquiere asimismo en la esfera religiosa andina, donde prima la relación ritual mutua entre númenes y seres humanos. 
equilibrio que, por su parte, depende del ethos religioso con el que los runakuna vivencian sus relaciones de reciprocidad con la tierra, pero cuya búsqueda ritual indica, al mismo tiempo, la necesidad intrínseca que éstos tienen de ejercer un control efectivo sobre las ocurrencias ecológicas que influyen en su día a día productivo. Tanto es así que podríamos calificar a los que en los Andes se conocen principalmente como rituales de «pago» a la tierra como una forma de reciprocidad basada, siguiendo a Descola (2001: 112), en una «oblación a no humanos divinos a cambio de la perpetuación de una dominación exitosa sobre no humanos animales y vegetales».

Así las cosas, la práctica social y ritual que involucra a runakuna y númenes telúricos en sus relaciones de intercambio simbólico-productivo, pone de manifiesto el hecho de que existe una equivalencia sustancial entre ambas partes, y no sólo en la eficacia material que éstas buscan lograr la una sobre la otra, sino también en la interioridad anímica con la que les es posible relacionarse más allá de sus «fisicalidades» corporales. Esta interioridad compartida constituye un factor altamente significativo dentro de la dialéctica comunicativa que se da entre runakuna y tierra, porque permite debatir hasta qué punto las creencias y prácticas que integran el animismo religioso andino pueden incluirse en una definición de la religión elaborada en referencia a lo «sobrenatural». Manuela Cantón (2001: 19) explica que lo «sobrenatural» es una característica «que permite diferenciar la religión de otros subsistemas de la cultura». Añade además que ésta «se sostiene sobre la creencia en la existencia de un mundo poblado de fuerzas invisibles, dioses, espíritus y otras entidades sobrenaturales», que esta antropóloga califica en términos generales como «poderes, a menudo caracterizados como seres, que trascienden el poder humano y los procesos de la naturaleza».

Como ejemplos válidos, aunque generalizados e indicativos de la vigencia de una contraposición «naturaleza» / «sobrenaturaleza» en la praxis teórica actual, consideramos que quizá definiciones de este tipo no sean del todo aplicables a religiones complejas que, como la andina, incluyen junto a creencias y prácticas cristianas de procedencia colonial otras aducibles más bien a una cosmovisión religiosa de raíces preexistentes. Como Descola (2001: 102) sostiene recordando las tesis durkheimianas del hecho religioso, lo «sobrenatural» es una «categoría residual para todos los fenómenos que parecen incompatibles con el funcionamiento racional de las leyes del universo».

En nuestro caso específico hay creencias, concepciones y prácticas y elementos propios de los cultos telúricos andinos que, si bien integran «convergencias» e «intercambios» propios de las formas religiosas cristianas (Flores 2002: 468-469), no comparten los criterios de sobrenaturalidad que en cambio caracterizan a estas últimas.

Existen estudios recientes de ámbito quechua-andino que muestran el mismo escepticismo sobre el uso de terminologías religiosas tan generalizadas como la de «sobrenatural». En particular, Ricard (2007: 341) describe el universo religioso de los pastores de las altas tierras del Ausangate como una «religión de la inmanencia». $Y$ puesto que esas poblaciones andinas mantienen una cosmovisión local profundamente afín a la de los agricultores quechua del valle de Patakancha, va de sí que los cultos rituales que los runakuna tributan a la tierra son de igual modo inmanentes, en la medida en que se fundamentan en factores infra-naturales como son las funciones biológicas, las formas topográficas, los hechos ecológicos y las figuras activas del entorno físico. 
La infra-naturalidad constituye, a nuestro juicio, una condición esencial de la ontología simbólica de personalización, socialización y personificación del ecosistema telúrico centro-andino, pues condensa todos aquellos aspectos biológicos, topográficos y ecológicos concebidos como «humanamente animados» por los runakuna por cuanto, como hemos analizado a la luz de las tesis rappaportianas, manifiestan:

a) una «numinosidad referencial», identificada con la tierra productiva (agraria y silvestre) vivificada como un ser físico dotado de personalidad e individualidad propia (alias, un ser humanizado y con sus propios apelativos sagrados);

b) «poderes divinos de acción», relacionados con la dialéctica ecológica local, sobre la cual la tierra humanizada influye conscientemente a través de sus facetas y contrapartes topográficas y ambientales (montañas, lluvia, etc.).

De cierta manera, estos aspectos cualitativos ponen incluso en discusión otro fundamento terminológico de la Antropología religiosa: la «divinización» como categoría simbólica propia de la antigua tradición espiritual greco-romana (y de la actual judeo-cristiana), cuya visión acerca de «dioses hechos a imagen y semejanza humana» no es contemplada por las cosmovisiones amerindias bajo los mismos términos simbólicos, por lo menos no en los elementos y fenómenos cosmológicos preexistentes que éstas preservan. Así, en nuestro caso específico, cuando en el imaginario patakanchino la tierra rebasa su fisicalidad material para encarnarse oníricamente en elementos personificados animales o humanos, lo hace para surtir efectos concretos en el plano ritual, esto es, toda vez que los runakuna advierten que hace falta reparar una negligencia alimentaria hacia ese elemento de sustento. Lo cual significa que, lejos de cualquier implicación idolística, las personificaciones telúricas patakanchinas se sirven de figuras icónicas (sapos, mofetas, mujeres del ayllu) que actúan como índices empíricos relacionados con la propiciación vegetal y agrícola, más bien que como deidades personales tributarias de veneración directa.

Es en esta línea discursiva cómo, por lo tanto, los cultos vinculados a la productividad telúrica en el valle de Patakancha expresan no sólo una religiosidad (paralela al cristianismo) entendida como conjunto de «símbolos y rituales que no están necesariamente regulados por la religión establecida» (Arregi y Manterola 1988: 572); sino también un complejo de lógicas simbólicas que no contemplan la concepción humana de un principio abstracto que trascienda el ámbito material, por cuanto se alimentan de referencias consustanciales a propiedades topográficas y ecológicas propias de la tierra andina, y que aquí hemos desglosado bajo terminologías conceptualmente renovadas como las de «numinoso», «sagrado», «divino», «infra-natural», etc. En este sentido, apuntamos en definitiva a que nuestro análisis etnográfico del simbolismo animista de los runakuna patakanchinos conlleve implicaciones teóricas sugerentes para la Antropología americanista actual, capaces de ampliar el campo aplicativo de las ontologías descolianas a cosmovisiones amerindias que, como las andinas, se expresan en contextos socio-ambientales distintos del amazónico.

AGRadecimientos: Las temáticas de este artículo forman parte de una investigación doctoral, desarrollada gracias a una Ayuda de Formación de Personal Investigador de la Universidad de Salamanca (España), cofinanciada por el Banco Santander. 


\section{Referencias bibliográficas}

AlaBí, Alberto

1996 «La tierra en la ciudad o 'Pachamama, bendecime el auto'», en Entre el cielo y la Pachamama, Flora Guzmán et al., pp. 49-83. San Salvador de Jujuy: Universidad Nacional de Jujuy.

AlenCASTRE GutiÉRrez, Andrés y Georges DumÉZIL

1953 «Fête et usages des Indiens de Langui (province de Canas, département du Cuzco)». Journal de la Société des Américanistes 42: 1-118.

Allen, Catherine J.

2008 La coca sabe: coca e identidad cultural en una comunidad andina. Cuzco: Centro Bartolomé de Las Casas.

Arregi AzPeitia, Gurutzi y Ander Manterola AldekoA

1988 «Religiosidad popular», en Diccionario temático de antropología, Ángel Aguirre Baztán, ed., pp. 572-578. Barcelona: Promociones y Publicaciones Universitarias.

Augé, Marc

1998 Dios como objeto. Símbolos-cuerpos-materias-palabras. Barcelona: Gedisa Editorial.

BIERSACK, Aletta

1999 «Introduction: from the 'New Ecology' to the New Ecologies». American Anthropologist 101 (1): 5-18.

Bouysse-Cassagne, Thérèse y Olivia Harris

1987 «Pacha: en torno al pensamiento aymara», en Tres reflexiones sobre el pensamiento andino, Thérèse Bouysse-Cassagne et al. eds., pp. 11-59. La Paz: Hisbol.

CÁCERES Chalco, Efraín

2007 «Visión y función del hamp'atu [sapo] en la cultura indígena andina: una lectura de simbologías y significados». Volveré 24. http://www.iecta.cl/revistas/volvere_24/articulo_3_volvere_24.htm

Cantón Delgado, Manuela

2001 La razón hechizada: teorías antropológicas de la religión. Barcelona: Ariel.

Casaverde Rojas, Juvenal

1970 «El mundo sobrenatural en una comunidad». Allpanchis Phuturinqa 2: 121-243.

CAYÓn ARMElia, Edgardo

1971 «El hombre y los animales en la cultura quechua». Allpanchis Phuturinqa 3: 135162.

Chávez Chaparro, Jorge

1950 «Distribución geográfica de los principales mamíferos peruanos». Revista Universitaria 39 (99): 233-321.

CONTRERAs Hernández, Jesús

1983 «Subsistencia y ritual en Chinchero (Perú)». Boletín Americanista 33: 195-222.

CUSIHUAmán GutiérRez, Antonio

2001 Diccionario quechua Cuzco-Collao. Cuzco: Centro Bartolomé de Las Casas. 
DALLE, Luis

1969 «El despacho». Allpanchis Phuturinqa 1: 139-154.

DeCOSTER, Jean-Jacques

1994 The Cultural Production of Collective Identity in an Andean Community. Tesis doctoral. Cornell University.

Descola, Philippe

1993 Les lances du crépuscule. Relations jivaros, Haute-Amazonie. París: Plon.

1996 La selva culta. Simbolismo y praxis en la ecología de los Achuar. Quito: Abya Yala.

2001 «Construyendo naturalezas», en Naturaleza y sociedad: perspectivas antropológicas, Philippe Descola y Gísli Pálsson, eds., pp. 101-123. México: Siglo XXI Editores.

2012 Más allá de naturaleza y cultura. Buenos Aires: Amorrortu Editores.

Descola, Philippe y Gísli PÁlsson

2001 «Introducción», en Naturaleza y sociedad: perspectivas antropológicas, Philippe Descola y Gísli Pálsson, eds., pp. 11-33. México: Siglo XXI Editores.

Di Salvia, Daniela

2014 La religión de la tierra en los Andes Centrales: imágenes simbólicas y trasfondos ecológicos. Salamanca: Ediciones Universidad de Salamanca.

EARLS, John D.

1982 La organización del poder en la mitología quechua. Urbana: University of Illinois.

\section{ESTERMANn, Josef}

1998 Filosofía andina. Estudio intercultural de la sabiduría autóctona andina. Quito: Abya Yala.

FERNÁNDEZ JuÁREZ, Gerardo

1997 Entre la repugnancia y la seducción: ofrendas complejas en los Andes del Sur. Cuzco: Centro Bartolomé de Las Casas.

Flores OCHOA, Jorge A.

1972 «Y estas idolatrías no pudieron ser extirpadas». Revista Saqsaywamán del Patronato Departamental de Arqueología 2: 195-210.

1977 «Enqa, enqaychu, illa y khuya rumi», en Pastores de Puna: Uywamichiq Punarunakuna, Jorge A. Flores Ochoa, comp., pp. 211-237. Lima: Instituto de Estudios Peruanos.

1998 «La missa andina», en Actas del IV Congreso Internacional de Etnohistoria, pp. 99-115. Lima: Fondo Editorial Pontificia Universidad Católica del Perú.

2002 «Ceremonias religiosas: continuidad o cambio en el sur andino», en Incas e indios cristianos. Elites indigenas e identidades cristianas en los Andes coloniales, JeanJacques Decoster, ed., pp. 459-474. Cuzco: Centro Bartolomé de Las Casas.

GöLTE, Jürgen

1980 La racionalidad de la organización andina. Lima: Instituto de Estudios Peruanos.

Gow, Rosalind y Bernabé Condori

1976 Kay Pacha. Cuzco: Centro Bartolomé de Las Casas. 
Granadino, Cecilia y Cronwell JARA JimÉneZ

1996 Las ranas embajadoras de la lluvia y otros relatos. Cuatro aproximaciones a la Isla de Taquile. Lima: Minka.

Guamán Poma De Ayala, Felipe

1980 Nueva crónica y buen gobierno [1615]. Biblioteca Ayacucho 75-76. Trascripción, prólogo, notas y cronología de Franklin Pease. Caracas: García Yrigoyen.

Jimeno SALVATIERRA, Pilar

2006 La creación de cultura: signos, símbolos, antropología y antropólogos. Madrid: Universidad Autónoma de Madrid.

KoTTAK, Conrad P.

1999 «The New Ecological Anthropology». American Anthropologist 101 (1): 23-35.

Kusch, Rodolfo

1977 El pensamiento indígena y popular en América. Buenos Aires: Hachette.

Manga QeSPI, Atuq E.

1994 «Pacha: un concepto andino de espacio y tiempo». Revista Española de Antropología Americana 24: 155-189.

Mariscotti De GöRlitz, Ana María

1978 Pachamama Santa Tierra. Contribución al estudio de la religión autóctona en los Andes centro-meridionales. Suplemento de Indiana 8. Berlín: Gebr. Mann Verlag.

MARzAL, Manuel María

1971 El mundo religioso de Urcos: un estudio de antropología religiosa y de pastoral campesina de los Andes. Cuzco: Instituto Pastoral Andina.

1985 El sincretismo iberoamericano: un estudio comparativo sobre los quechua (Cuzco), los maya (Chiapas) y los africanos (Bahía). Lima: Pontificia Universidad Católica del Perú.

Mejía Huamán, Mario

2005 Hacia una filosofía andina. Doce ensayos sobre el componente andino de nuestro pensamiento. Lima: Edición del autor.

MiLlONES, Luis

2011 «El bestiario del Manuscrito de Huarochirí», en Manuscrito de Huarochirí. Libro sagrado de los Andes peruanos, versión bilingüe quechua-castellano de José María Arguedas, Jorge I. Úzquiza González, ed., pp. 23-32. Madrid: Editorial Biblioteca Nueva/Universidad de Extremadura.

NúÑez Del Prado BéJAR, Juan V.

1970 «El mundo sobrenatural de los quechuas del sur del Perú a través de la comunidad de Qotobamba». Allpanchis Phuturinqa 2: 57-119.

OrTIZ RESCANIERE, Alejandro

1992 El quechua y el aymara. Madrid: MAPFRE.

Puente Ojea, Gonzalo e Ignacio Careaga Villalonga

2005 Animismo. El umbral de la religiosidad. Madrid: Siglo XXI de España Editores.

RAPPAPORT, Roy A.

1975 «Naturaleza, cultura y antropología ecológica», en Hombre, cultura y sociedad, Harry L. Shapiro, ed., pp. 261-292. México: Fondo de Cultura Económica. 
2001 Ritual y religión en la formación de la humanidad. Madrid: Cambridge University Press.

RiCARD LANATA, Xavier

2007 Ladrones de sombra. El universo religioso de los pastores del Ausangate (Andes surperuanos). Cuzco: Centro Bartolomé de Las Casas.

Roca WallParimachi, Demetrio

1966 «El sapo, la culebra y la rana en el folklore actual de la pampa de Anta». Folklore: Revista de la Cultura Tradicional 1 (1): 41-65.

RösING, Ian

1994 «La deuda de ofrenda: un concepto central de la religión andina». Revista Andina 12 (1): 191-216.

Rostworowski De Diez CANSECo, María

1976 «Reflexiones sobre la reciprocidad andina». Revista del Museo Nacional 42: 341354.

SÁNCHEZ, Rodrigo

1982 «La teoría de lo andino y el campesinado de hoy». Allpanchis Phuturinqa 20: 255281.

SÁNCHEZ GARRAFA, Rodolfo

1995 «Espacio y estructuras religiosas en los mitos del Ausangate». Antropológicas 13: 167-185.

SANTAMARINA CAmpos, Beatriz

2008 «Antropología y medio ambiente. Revisión de una tradición y nuevas perspectivas de análisis en la problemática ecológica». AIBR. Revista de Antropología Iberoamericana 3 (2): 144-184.

TAMAYo Herrera, José A.

1970 «Algunos conceptos filosóficos de la cosmovisión del indígena quechua». Allpanchis Phuturinqa 2: 245-254.

TAYLOR, Gerald

1999 Ritos y tradiciones de Huarochirí. Lima: Instituto Francés de Estudios Andinos/ Banco Central de Reserva del Perú/Universidad Particular Ricardo Palma.

Tuero Villa, Juan V.

1994 «La ceremonia del Qarakuy y el pago a la Pachamama». Revista Andes 1: 189203.

TYLOR, Edward B.

1981 Cultura primitiva. II, La religión en la cultura primitiva [1871]. Madrid: Ayuso.

VALDERrama Fernández, Ricardo y Carmen EsCALANTE GutiérRez

1976 «Pacha T'inka o la T'inka a la Madre Tierra en el Apurímac». Allpanchis Phuturinqa 9: 177-241.

1978 «Mitos y leyendas de los quechuas del sur del Perú». Debates en Antropología 2. Lima: Pontificia Universidad Católica del Perú.

1988 Del Tata Mallku a la Mama Pacha. Lima: DESCO. 